\title{
DELINEAMENTO DE ÁREAS COM POTENCIAL EROSIVO PARA A BACIA HIDROGRÁFICA DO RIO PARANAÍBA (PN1-IGAM)
}

\author{
Ivair Gomes ${ }^{1}$, Eliane M. Vieira ${ }^{2}$, Marley L. Machado ${ }^{3}$, Maria L. R. Simão ${ }^{3}$, Arlon C. Ferreira ${ }^{4}$
}

\author{
Programa de Pós-Graduação em Geografia, Universidade Federal de São João del-Rei (Campus Ctan). Av. Visconde do Rio Preto s/n, CEP 36.302-360, São João \\ del-Rei, Brasil. (ivair@ufsj.edu.br; autor correspondente) \\ Departamento de Engenharia Ambiental, Universidade Federal de Itajubá, Brasil. \\ Laboratório de Geoprocessamento, Empresa de Pesquisa Agropecuária de Minas Gerais, Av. José Cândido da Silveira, 1647 - Cidade Nova, Belo Horizonte, \\ CEP 31.170-495 \\ Programa de Pós-Graduação em Geografia, Universidade Federal Fluminense (Campus Praia Vermelha), Av. Gal. Milton Tavares s/n - Boa Viagem, Niterói, CEP \\ 24.210-346
}

Recebido em 10 de janeiro de 2019, aceito em 15 novembro de 2019

Resumo: A identificação do potencial erosivo de uma área antes que ele se manifeste é de grande importância para mitigar impactos ambientais negativos e evitar prejuízos econômicos ao uso do solo. Assim esse trabalho teve como objetivo identificar as áreas com maior potencial de sofrer processos erosivos na Bacia Hidrográfica PN1 (o Instituto Mineiro de Gestão de Águas dividiu a área da Bacia do Rio Paranaíba, em MG, em: PN1, PN2 e PN3). Por meio do emprego do Sensoriamento Remoto e de Sistemas de Informação Geográficas, foram feitas a identificação das áreas mais suscetíveis a um processo erosivo, bem como a manipulação das variáveis inerentes a esse processo, que atuam na bacia. Foram avaliados os tipos de solo, uso da terra, relevo e outros parâmetros necessários ao entendimento da dinâmica erosiva na bacia e calculada Equação Universal de Perdas de Solos (EUPS) para os diferentes cenários de uso do solo. Para obtenção dos resultados foram elaborados mapas de erodibilidade e erosividade que permitiram dar uma indicação das principais áreas de risco erosivo em cada cenário de uso. Os resultados apresentados para o potencial erosivo, foram abordados de forma qualitativa, com cenários onde se empregam e onde não se empregam práticas conservacionistas.

Palavras-Chave: Bacia Hidrográfica; Solo; SIG; Conservação do solo; Erosão.

Abstract: The identification of the erosive potential of area before it manifest it self of great importance to mitigate the risky circumstances and to avoid demages to the use of the ground. The aim of this work was to identify the áreas with the greatest potential to undergo erosive processes in the PN1 Hidrographic Basin (the Minas Gerais Water Management Institute divided the area of the Paranaíba River Basin in MG in PN1, PN2 and PN3). Through the use of Remote Sensing and Geographic Systems, the most sensitive áreas to na erosive process were identified, as wall as the manipulation of the variables inherent in this process, which operate in the basin. The soil types, land use, relief and other parameters required to understand erosion dynamics in the basin and calculated the Universal Soil Loss Equation (EUPS) for the diferente land use scenarios were evaluated. In order to obtain the results, erodibility and erosivity maps were elaborated to give an indication of the main areas of erosive risk in each use scenario. The results were presented for the erosive potential, were applied in a qualitative way, with the use and where they are not used conservationist practices. As a result, erodibility and erosivity maps were elaborated that allow the indication of the main áreas of erosive risk in each use scenario.

Keywords: Basin Hydrographic; Soil; GIS; Soil Conservations; Erosion.

\section{INTRODUCÃO}

Este trabalho propõe a identificação das áreas mais susceptíveis a um processo erosivo bem como a manipulação das variáveis inerentes a esse processo que atuam na microbacia PN1 (o IGAM dividiu a área da Bacia do Rio Paranaíba em: PN1, PN2 e PN3) (Figura 01). Ele é parte de um projeto de pesquisa financiado pela FAPEMIG que, além da identificação das áreas procurou promover o aprendizado e a conscientização ambiental, através da realização de palestras e elaboração de uma cartilha educativa que foram desenvolvidos no âmbito do projeto.

Neste trabalho, a perda de solo foi calculada por meio da Equação Universal de Perdas de Solo (EUPS). A EUPS foi desenvolvido em 1954, com base na análise dos dados de escoamento superficial e perdas de solo obtidos em mais de 10.000 parcelas experimentais, em condições de chuvas naturais e simuladores, por pesquisadores da Universidade de Purdue (EUA). Em 1978 Wischmeier e Smith (1978) fizeram com que a equação evoluísse para um modelo computacional que expressa a perda anual de solo por unidade de área, considerando seis fatores independentes: perda de solo por unidade de área, erosividade da chuva, erodibilidade do solo, distância ao longo da qual ocorre o escoamento superficial, declividade do terreno, uso e manejo do solo.
O fator manejo de solo pode ser modelado por meio de cenários onde pode-se ou não adotar práticas conservacionistas.

Embora a EUPS tenha sido desenvolvido para pequenos talhões, compatível com o uso agrícola, Farinasso et al., (2006) descreve que a mesma pode ser empregada em grandes áreas ou em escalas regionais, permitindo avaliar qualitativamente e geograficamente as áreas de diferentes graus de susceptibilidade à erosão. Stein et al., (1987) concluíram que a EUPS, para grandes áreas, não deve ser utilizada como estimativa para quantificar perdas de solo por erosão, mas para uma avaliação qualitativa (apud FERINASSO et al., 2006).

A Bacia Hidrográfica situa-se nas mesorregiões do Triângulo Mineiro e Alto Paranaíba, onde estão municípios como Uberlândia, Patrocínio e Patos de Minas, Agregando um total de 18 sedes municipais, a bacia possui uma população estimada de 434.241 habitantes e uma área de drenagem de $22.291 \mathrm{~km}^{2}$. O clima na bacia é considerado semi-úmido, com período seco durando entre quatro e cinco meses por ano, situando-se a disponibilidade hídrica entre 10 e 20 litros por segundo por quilometro quadrado.

\section{METODOLOGIA}

O trabalho teve como base o uso de Sistema de 


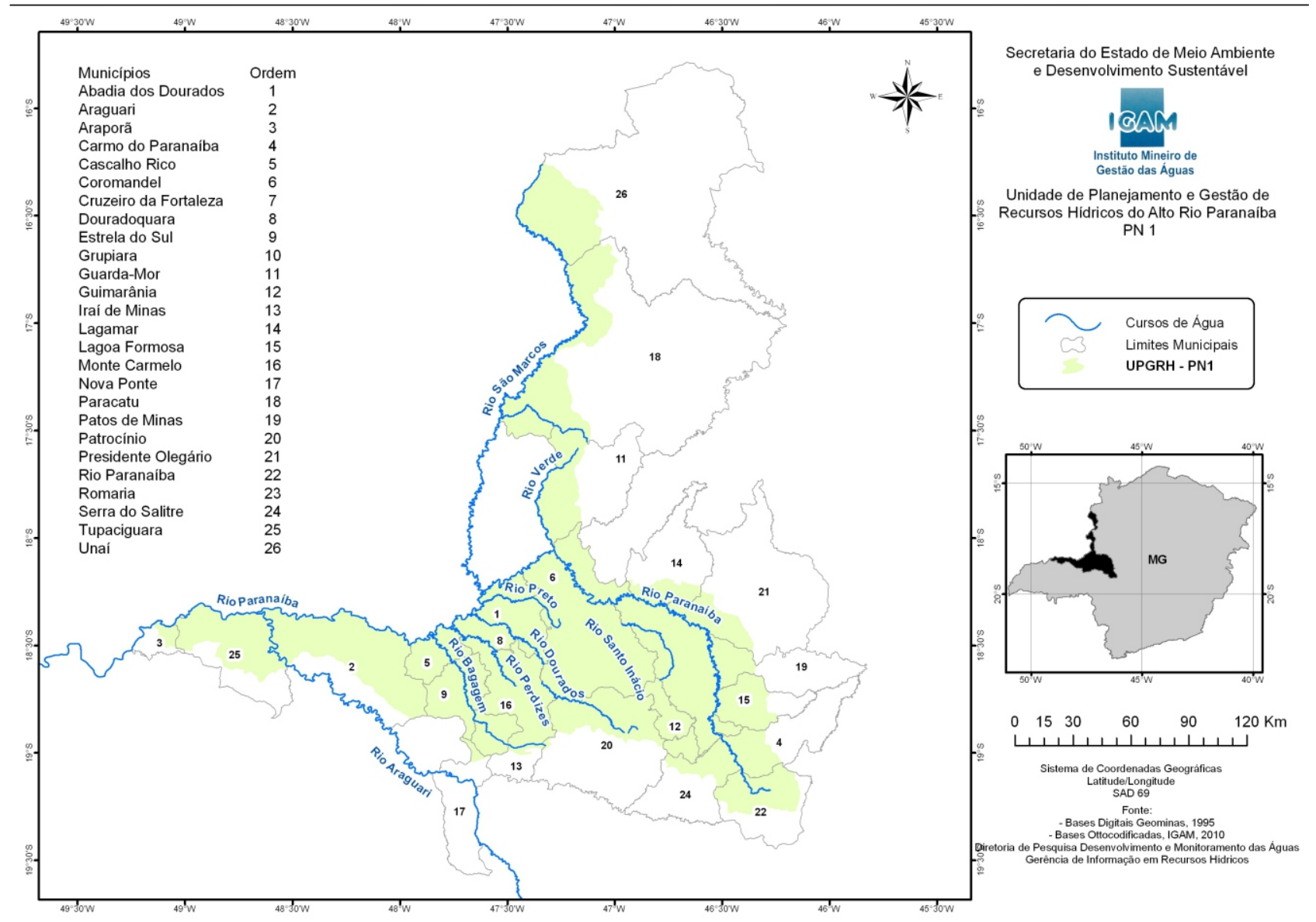

Figura 1-Área de estudo. Bacia do rio Paranaíba (IGAM/PN1). Fonte: Instituto Mineiro de Gestão das Águas (2018).

Informações Geográficas (SIG), trabalhando com bases de dados georreferenciados. Para o desenvolvimento das atividades foram empregados os sistemas ArcGis $9.2 \mathrm{e}$ Spring 5.0. A equação universal de perda de solo (EUPS) (Equação 1) empregada neste trabalho foi adotado por Wischmeier e Smit (1978).

Equação 1: Modelo de equação proposto por Wischmeier e Smith (1971).

\section{Pu=R.K.(L.S)C.P}

Pu: perda de solo por unidade de área, tha- ${ }^{1}$ ano- ${ }^{1}$

$\mathrm{R}$ : fator erosividade da chuva, $\mathrm{MJ} \mathrm{ha-} \mathrm{-}^{1} \mathrm{~mm} \mathrm{~h}^{-1}$ ano- ${ }^{1}$.

K: fator erodibilidade do solo, (t ha-1)/(MJ ha-1 $\mathrm{mm} \mathrm{h}^{-1}$;

$L$ : fator que leva em conta a distância ao longo da qual ocorre o escorregamento superficial, adimensional:

$\mathrm{S}$ : fator que considera a declividade do terreno, adimensional;

C: fator que leva em conta o uso e manejo do solo, adimensional; $e$

$\mathrm{P}$ : fator que considera as práticas conservacionistas adotadas, admensional.

Para o trabalho foram empregados os materiais: mapas de solos na escala 1:500.000, Shuttle Radar Topography Mission (STRM) em pixel de $90 \times 90 \mathrm{~m}$, imagens LandSat 5 de setembro de 2008.

\section{Fator " $R$ "}

O fator " $R$ " foi estabelecido a partir da equação proposta por Silva (1997) estabelecido para a região de Goiânia, visto que, entre os modelos estabelecidos é o que mais se aproxima da região por apresentar características climáticas semelhantes às áreas da área de estudo.

Foram empregados estações pluviométricas da ANA presentes na região co série histórica superior a 15 anos. Depois de calculada a média mensal para cada estação estas foram atribuídas ao banco de dados do plano de informação contento a localização pontual de cada estação e por meio do interpolador IDW (Inverso da Distância Ponderado), foi estimado o valor da precipitação média para cada célula, considerando-se uma resolução espacial de $90 \mathrm{~m}$ (a mesma resolução do SRTM também empregado neste trabalho) e um peso igual a 2.

Também foi calculada a média anual para cada estação e, assim como para a média mensal, estes valores também foram atribuídos ao banco de dados do plano de informação e interpolados para toda a bacia por meio do IDW, também com resolução espacial de 90 m e peso 2 .

Para a área de estudo foi empregado o coeficiente de chuva proposto por Founier (1956) e modificado por Lombardi Neto e Moldenhauer (1977) (Equação 2).

Equação 2: Coeficiente de chuva adotado.

$$
\begin{aligned}
& \quad \mathbf{E I}=\mathbf{p}^{2} / \mathbf{P} \\
& \text { Sendo: } \\
& \text { El: média mensal do índice de erosão; } \\
& \text { p: precipitação média mensal, mm; } \\
& \text { P: precipitação média anual, } \mathrm{mm} \text {. }
\end{aligned}
$$

A erosividade média mensal, dada em MJ ha-1 h-1, foi obtida por meio da equação 3, proposta por Silva (1997).

Equação 3: Erosividade média mensal.

\section{$\mathrm{El}_{30}=216,15+30,69 \mathrm{EI}$}

Onde El é a média mensal do índice de erosão obtido por meio da equação 2 . 


\section{Fator "K"}

Foram compilados valores para o fator $\mathrm{K}$ (fator erodibilidade do solo) de alguns solos do Brasil disponíveis na literatura para unidades pedológicas similares às da área em estudo, selecionando trabalhos onde os valores foram adquiridos em experimentos por método direto (experimentos em campo constituídos por parcelas experimentais onde foram avaliadas a erodibilidade). Estes valores encontrados foram associados aos solos da área em estudo em função de suas características físicas. Para a região em estudo foram utilizados os levantamentos de solos, escala 1:500.000 para o Triangulo Mineiro (GOMES et al., 1982); levantamento de solos para a região do Alto Paranaíba (MOTTA et al., 2004); levantamento de solos para a Região Geoeconomica de Brasília (NAIME ET AL., 1998), sendo os mapas analógicos rasterizados, georreferenciados e digitalizados no ArcGis.

\section{Fator " $L$ "}

Para o cálculo do fator LS ( $L$ - fator que leva em conta a distância ao longo da qual ocorre o escoamento superficial e $\mathrm{S}$ - fator que considera a declividade do terreno) foi usado uma grade altimétrica proveniente do satélite Shuttle Radar Topography Mission (SRTM) em pixel de 90 x $90 \mathrm{~m}$. O Fator "L" foi calculado conforme metodologia emprega por Desmet e Govers (1996), citado por Farinasso et al., (2006).

A área de contribuição de cada célula foi calculada por meio da geração da direção de fluxo e posteriormente o fluxo acumulado, sendo a área de contribuição equivalente à área da célula multiplicada pelo fluxo acumulado. Com o emprego do SIG ArcGIS para este trabalho, foi possível simular 8 direções para a direção de fluxo, conforme o código do algoritmo denominado eight-direction pour point algorithm (D-8), adotado por este SIG, que permite definir um código de direção de escoamento para cada célula.

Neste algoritmo é atribuído a cada célula um código que indica a direção do fluxo, de acordo com a altitude das oito células vizinhas, considerando-se que o fluxo atenderia a direção da célula de maior declividade ao redor da célula analisada.

\section{Fator "S"}

O fator "S" foi calculado conforme metodologia empregado por Wishmeier e Smith (1978). Para a obtenção de todos os parâmetros necessários a esta equação foram empregados os dados altimétricos obtidos pelo satélite Shuttle Radar Topography Mission (SRTM), com $90 \mathrm{~m}$ de resolução espacial.

O MDT é uma fonte importante, e frequentemente usada, para a obtenção de dados relativos ao fluxo superficial, como a rede de drenagem e bacias de contribuição, pois é a elevação o fator que mais interfere nestes tópicos (Duke et al., 2003).

Utilizando o módulo 3D Analyst do ArcGIS 9.3, foi necessário que se eliminassem todas as depressões indevidamente geradas durante o processo de obtenção do sensor, pois estas depressões impedem ou desviam o escoamento superficial, o que acarretaria em uma delimitação errônea da direção do fluxo e consequentemente do fluxo acumulado.

Empregando-se o módulo hidrológico do ArcGIS 9.3, foi possível gerar o mapa contendo as direções de fluxo para a área de estudo e o mapa contendo o fluxo acumulado. Também foi gerado o mapa de declividades (em \%) para a PN1, por meio do módulo 3D Analyst do software ArcGIS 9.3, este mapa foi reclassificado adotando-se as classes propostas por Desmet e Govers (1996), para a elaboração do mapa de coeficientes $m$.

Utilizando-se a ferramenta "Map Calculator" foram agregados todos os fatores na equação de Desmet e Govers (1996), chegando-se ao fator L.

O plano de informação contendo a declividade da bacia também foi empregado para o cálculo do fator " $\mathrm{S}$ ", utilizando-se também o "Map Calculator" para a solução da equação proposta por Wishmeier \& Smith (1978).

Foi feita a aquisição de imagens de satélites para a área de estudo, com a intenção de fazer a classificação do uso da terra. Optou-se, devido à disponibilidade das imagens, por sua adequabilidade ao projeto e pelo fato de não terem custos, pelo uso de imagens do satélite LandSat 5, composição RGB-345.

Para a classificação do uso da terra foram feitas campanhas de campo por três pesquisadores e dois bolsistas em que, num período de 7 a 15 dias, levantaram informações acerca do uso da terra, georreferenciando cada unidade produtiva.

A partir das classes de uso da terra foram feitas campanhas de campo realizadas em novembro de 2008, para validar a classificação das imagens. Após a classificação e validação dessas imagens foi atribuído o percentual vegetativo para as diferentes classes de uso da terra.

\section{Fator " $C$ "}

Para o fator " $C$ " (fator que leva em conta o uso e manejo do solo) foram feitas revisões bibliográficas para valores levantados para as diversas culturas detectadas na região.

\section{Fator " $\mathrm{P}$ "}

Para o fator " $P$ " (fator que considera as práticas conservacionistas adotadas) foram feitas revisões bibliográficas para valores levantados para as práticas conservacionistas detectadas e georreferenciadas na região durante os levantamentos de campo e atribuído a cada classe de uso e cobertura considerando-se dois cenários: com práticas conservacionistas e sem práticas conservacionistas. Foi então, estabelecido um modelo matemático de perda de solo que mais se adéqua à realidade local e então, a partir dos planos de informação levantados preliminarmente, foram aplicados na geração do mapa de potencial erosivo para a região.

Os mapas foram gerados na escala mínima de 1:500.000 de forma a se obter boa representatividade da área. 
Todo o trabalho foi colocado na forma digital com a finalidade de proporcionar maior flexibilidade na obtenção de resultados e maior facilidade no manuseio. Após a identificação das áreas contribuintes no processo erosivo foram avaliados os resultado da delimitação do potencial erosivo nestas regiões.

\section{RESULTADOS}

\section{Fator " $R$ "}

Para o cálculo do fator " $R$ " foram utilizados dados das estações da ANA localizadas dentro e ao redor e na bacia em estudo e buscando uma boa distribuição espacial a fim que toda a área de estudo fosse recoberta. Para o processo de obtenção da média mensal foram utilizadas series históricas iguais ou superior a 15 (quinze) anos, totalizando 76 estações.

Para cada estação foi calculada a média mensal e anual e tais informações interpoladas por meio do IDW, com 90 $m$ de resolução espacial.

O coeficiente de chuva foi calculado para cada célula da bacia por meio da fórmula proposta por Fournier (1956), e a partir deste foram calculados o fator " $R$ " para cada célula por meio da equação proposta por Silva (1997). A e a apresentam os mapas de pluviometria por média mensal e de erosividade mensal para a região da bacia PN1.

Observa-se nas figuras 2 e 3 que, como esperado, os meses de abril a setembro apresentam pouco índice pluviométrico e consequentemente baixos índices de erosividade pela chuva.

A figura 4 apresenta o mapa para o El30 anual (Fator " $R$ " em MJ mm ha- ${ }^{1} \mathrm{~h}^{-1}$ ano- ${ }^{1}$ ) para a região PN1. Os valores encontrados foram extratificados em seis classes a fim de se visualizar a variação deste parâmetro ao longo da bacia. Assim, foi possível observar regiões com maior susceptibilidade a erosão pelas condições de precipitação nas classes com maiores valores de erosividade. O que significa as classes do mapa?

\section{Fator "K"}

Para o cálculo do Fator " $K$ " e união de suas bases foi empregado um mosaico das imagens LandSat do mês de setembro de 2008 sobre o qual foi adicionado o plano de informação contendo o limite das classes de solos no formato vetorial de cada mapa de solos separadamente, para posteriormente uni-los. Nessa etapa percebeu-se que os limites das classes dos diferentes levantamentos não coincidiam e em muitos casos a classe também se encontrava com classificações distintas, sendo portanto, necessário a correção dos limites, realizada pela identificação destes limites observando a textura, saturação e brilho da imagem, o relevo local, observado por meio do Modelo Digital de Elevação da bacia PN1 ( ) e por meio de viagens as campo para verificação in loco.

Nos trabalhos de campo foi possível identificar a classe de solo por meio da análise tátil-visual (onde são avaliados o teor de argila por meio tátil e a cor comparando-se com a tabela de Munsell), dispensando assim as análises de solos anteriormente previstas para tal identificação.

Foram editados e reclassificados conforme a nova classificação de solos, todos os polígonos na área de estudo, refinando seus limites diante da possibilidade oferecida pelas imagens Landsat 5, que se encontrava na escala de 1:50.000, e experiência da equipe em levantamento e classificação de solos, caba salientar que tal edição não visou alterar a escala original dos levantamentos (1:500.000) e sim editar na medida do possível o limite das classes quando a interpretação nas imagens assim o permitiam. Foram listadas as classes presentes na bacia e para tais foram feitas revisões bibliográficas a fim de se extrair os valores de $\mathrm{K}$ para estas. Nesta etapa selecionou-se os estudos realizados em regiões similares às encontradas na bacia e sempre que possíveis próximas a esta.

A apresenta os valores do fator $\mathrm{K}$ associados aos solos da região em estudo com base na similaridade com solos de outros locais levantados por experimentos de perda de solo.

Tabela 1. Valores de K para solos da área de estudo. *Grau de fertilidade não citado pela fonte.

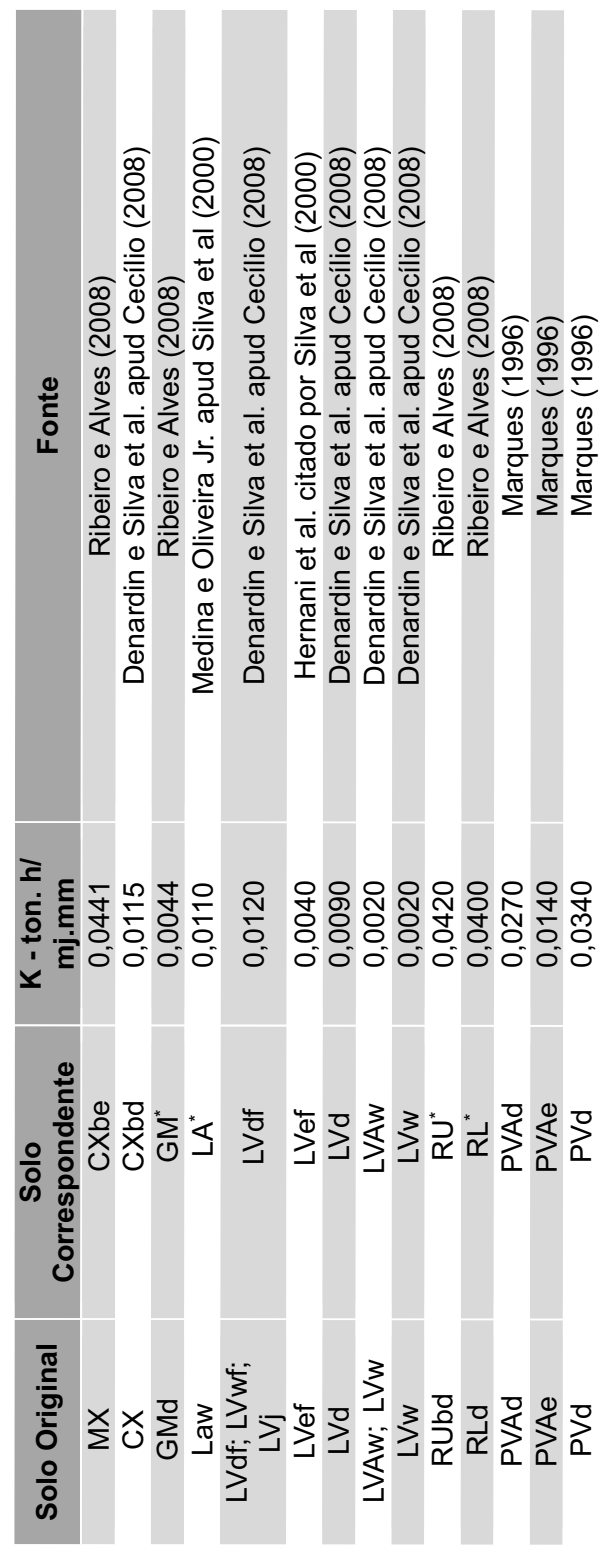



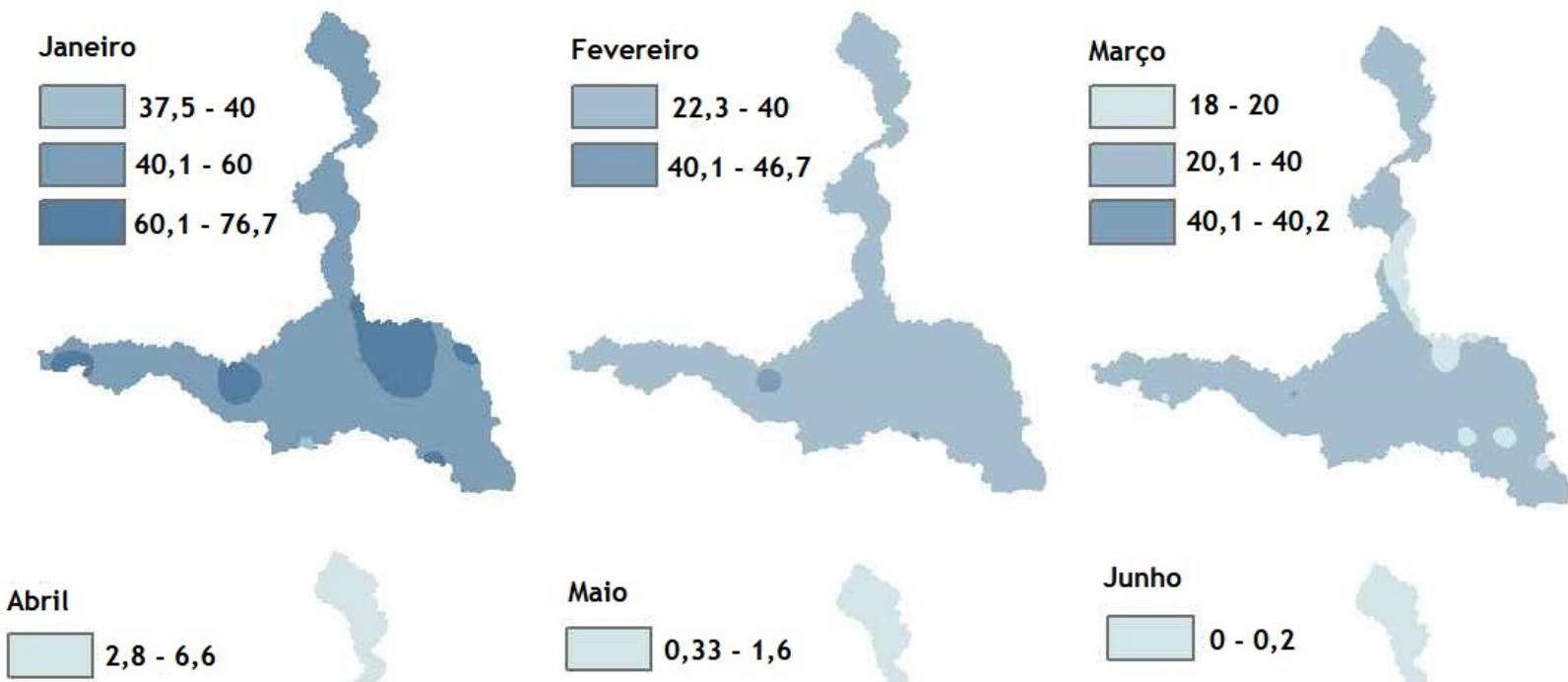

Maio

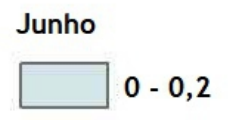

$0,33-1,6$

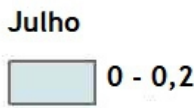

Agosto

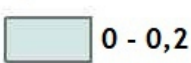

Setembro

$0,6-3$

\section{Outubro}

$6,6-12,9$

\section{Novembro}

ए 24,1 - 40

$40,1-46,3$
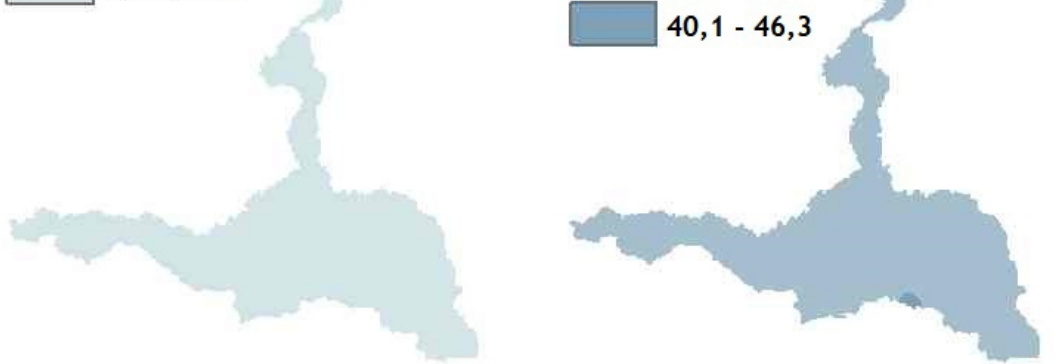

Dezembro

$\square 40,6-60$
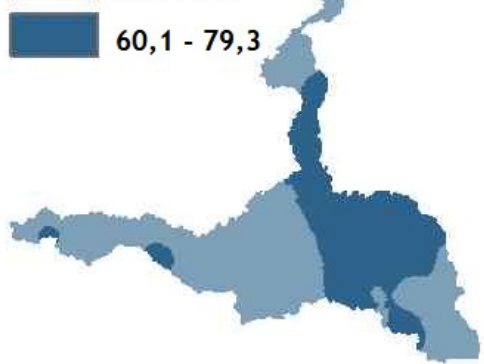

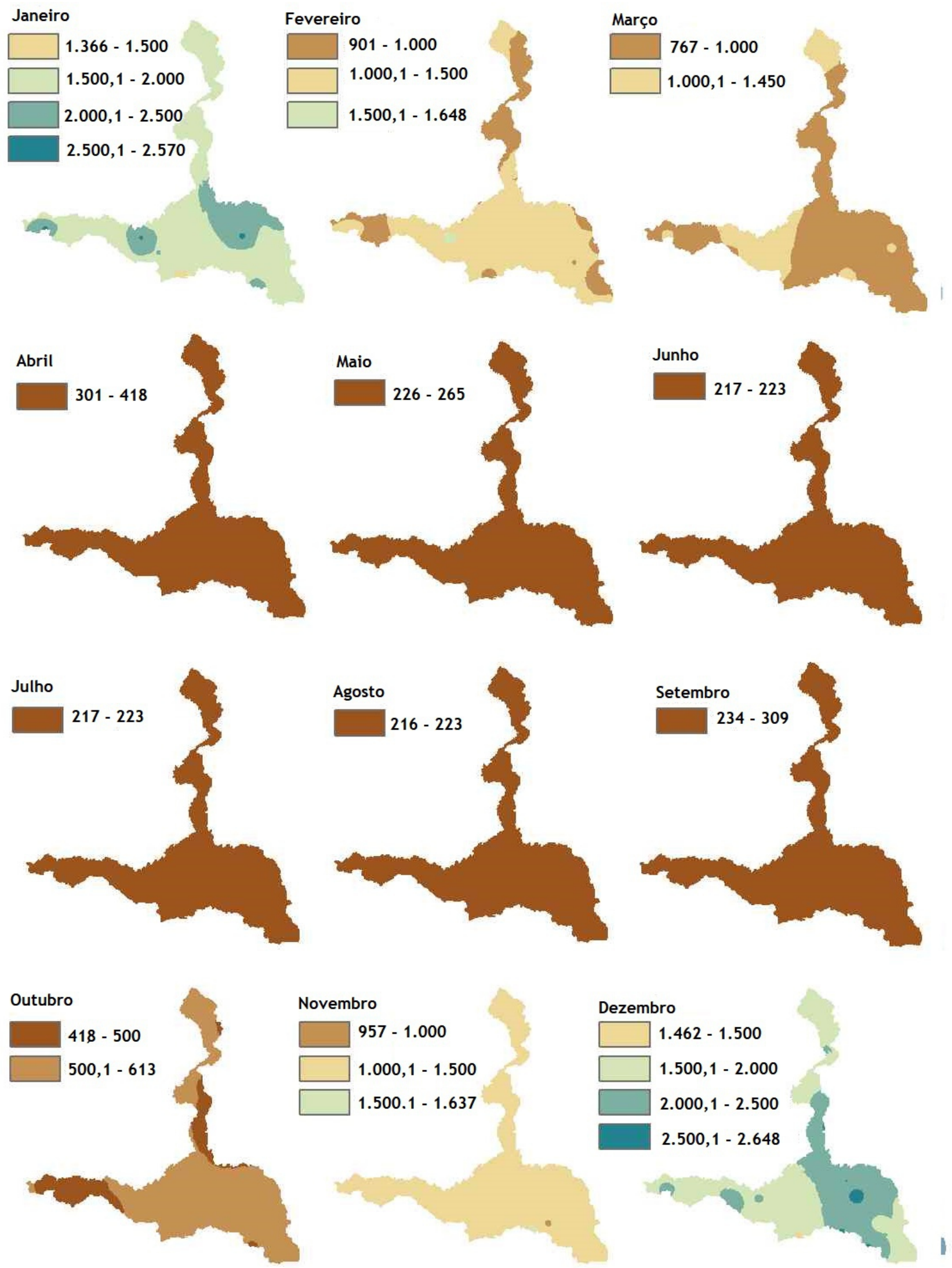
Os valores de $\mathrm{K}$ levantados na revisão bibliográfica foram associadas às classes de solos correspondentes por meio da edição do banco de dados referente ao mapa de solos reeditado para a região de estudo. Após a edição do banco de dados o mapa de solos foi reclassificado chegando-se ao mapa de Erodibilidade para a bacia Pn1.

\section{Fator " $\mathrm{L}$ "}

Objetivando calcular o Fator $L$ () foi gerado o mapa de direção de fluxo para a obtenção do mapa de fluxo acumulado a fim de se calcular a área de contribuição para cada célula. Para o parâmetro $D$ foi adotado o valor 90, correspondente à resolução espacial do SRTM e adotada para todos os mapas gerados.

Utilizando-se o Map Calculator foram agregados todos os fatores na equação de Desmet e Govers (1996), obtendose como resultado o fator $\mathrm{L}$, conforme apresentado no mapa 2.

Como pode ser observado na escala da legenda da figura 6, foram obtidos valores de 0,18 a 157,25 para a área de estudo. Embora estes resultados apresentem um grande espectro de valores, analisando o resultado, a grande maioria da área apresenta valores inferiores a 1.

A predominância de valores baixos também foi constada com a obtenção da média dos valores obtidos que foi de 0,48 com um desvio padrão de 0,67 .

Este resultado apresenta-se coerente com a área estudada, visto que em geral apresenta baixas declividades e uma densificada rede de drenagem.

\section{Fator "S"}

Foi gerado o mapa de declividade em percentagem para a área de estudo com a resolução espacial de $90 \times 90 \mathrm{~m}$, correspondente à resolução espacial do SRTM (base de dados empregada para este processo). O Fator "S" (Figura 7) foi obtido por meio do emprego da equação proposta por Wishmeier e Smith (1978) empregando-se o Map Calculator do SIG ArcGis.

Para este fator os valores variaram de 0,06 a 5,84 para a área de estudo. Sendo que a média dos valores para a área é de 0,35 , podendo ser considerado um valor baixo condizente com a topografia da região que apresenta poucas áreas (em relação a área total da bacia) com declividades mais acentuadas.

\section{Fator "C"}

Para a obtenção do fator " $C$ " foi feita uma revisão bibliográfica para diversas culturas, conforme apresentado na tabela 2. Paralelamente a esta revisão foram realizados trabalhos de campo para a coleta de pontos de controle para a classificação das imagens obtidas junto ao INPE do satélite Landsat 5.

A região é caracterizada por uma variedade de culturas, mas com grande presença de áreas de café, cana-deaçúcar, reflorestamento, pastagens anuais, matas ciliares e pastagens. As classes de uso e ocupação identificados na área de estudo foram agrupados em dez classes: Agricultura perene, agricultura anual, água, área urbana, café, cerrado, eucalipto mata, pastagem e pinus, Para
Tabela 2. Valores de cobertura vegetal (Fator "C").

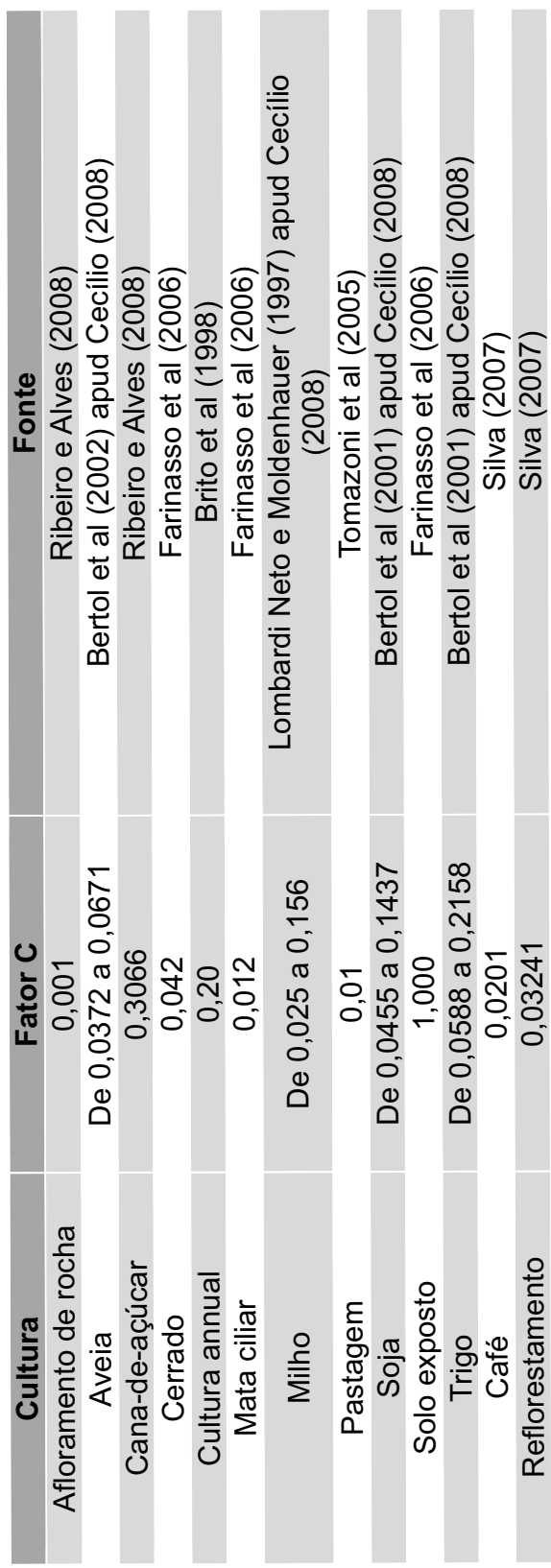

cada classe foi atribuído o valor correspondem ao fator " $C$ " como apresentado na Tabela 3 e figura 8.

Observando-se a figura 9 (mapa fator C-uso e manejo do solo), percebe-se que a bacia tem muitas áreas com elevada susceptibilidade à erosão (tons mais escuros maiores de 0,001) e que essas áreas são relativas às pastagens ou cerrados, culturas anuais, ou seja, atividades antrópicas.

Fator $\mathrm{P}$

Para definição do fator " $P$ ", foi realizado um estudo para definir o uso e ocupação do solo na área da PN1-IGAM. As classes delimitadas foram agricultura, água, área urbana, café, cerrado, eucalipto, mata, pastagem e pinus. Cada cultura oferece uma capacidade de proteção ao solo. A cada uma das classes, com o auxílio de bibliografias, foi atribuído um valor para P com o uso de práticas conservacionistas, bem como um valor para $\mathrm{P}$ sem o uso dessas práticas, conforme apresentado na tabela 4. 
Tabela 3. Valores de "C" para uso e ocupação dos solos da região em estudo.

\begin{tabular}{|c|c|}
\hline $\begin{array}{c}\text { Uso e ocupação do } \\
\text { solo }\end{array}$ & "C" \\
\hline Agricultura perene & 0,02 \\
\hline Agricultura anual & 0,2 \\
\hline Água & 0 \\
\hline Área urbana & 0 \\
\hline Café & 0,2 \\
\hline Cerrado & 0,01 \\
\hline Eucalipto & 0,001 \\
\hline Mata & 0,0001 \\
\hline Pastagem & 0,01 \\
\hline Pinus & 0,001 \\
\hline
\end{tabular}

Tabela 5. Descrição das classes de Erosão (Cenário 1) - Com práticas conservacionistas.

\begin{tabular}{|c|c|c|}
\hline $\begin{array}{c}\text { Classes de potencial de perdas } \\
\text { de solos }\end{array}$ & $\begin{array}{c}\text { Perdas de solo } \\
\text { Ton/ha/ano }\end{array}$ & Área em \% \\
\hline $\begin{array}{c}\text { Água e Área Urbana } \\
\text { Muito Baixa }\end{array}$ & 0 & 2,974 \\
\hline Baixa & $0-1$ & 96,613 \\
\hline Média & $2-5$ & 0,388 \\
\hline Alta & $6-10$ & 0,019 \\
\hline Muito Alta & $11-20$ & 0,004 \\
\hline TOTAL & $>20$ & 0,001 \\
\hline
\end{tabular}

Tabela 4. Valores de "P" para o uso e ocupação dos solos da área de estudo. Fonte: Adaptado de BERTONI; NETO (1990) e RESENDE;

\begin{tabular}{|c|c|c|}
$\begin{array}{c}\text { ALMEIDA (1985). } \\
\text { Uso e ocupação do } \\
\text { solo }\end{array}$ & $\begin{array}{c}\text { P com práticas } \\
\text { conservacionistas }\end{array}$ & $\begin{array}{c}\text { P sem práticas } \\
\text { conservacionistas }\end{array}$ \\
\hline Agricultura & 0,5 & 1,0 \\
\hline Água & 0 & 0 \\
\hline Área urbana & 0 & 0 \\
\hline Café & 0,5 & 1,0 \\
\hline Cerrado & 0,04 & 0,04 \\
\hline Eucalipto & 0,04 & 0,04 \\
\hline Mata & 0,01 & 0,01 \\
\hline Pastagem & 0,5 & 1,0 \\
\hline Pinus & 0,04 & 0,04 \\
\hline
\end{tabular}

Tabela 6. Descrição das classes de Erosão (Cenário 2) - Sem práticas conservacionistas.

\begin{tabular}{|c|c|c|}
\hline $\begin{array}{c}\text { Classes de potencial de perdas } \\
\text { de solos }\end{array}$ & $\begin{array}{c}\text { Perdas de solo } \\
\text { Ton/ha/ano }\end{array}$ & Área em \% \\
\hline Água e Área Urbana & 0 & 2,974 \\
\hline Muito Baixa & $0-1$ & 95,895 \\
\hline Baixa & $2-5$ & 1,040 \\
\hline Média & $6-10$ & 0,066 \\
\hline Alta & $11-20$ & 0,019 \\
\hline Muito Alta & $>20$ & 0,005 \\
\hline TOTAL & & $\mathbf{1 0 0 , 0 0 0}$ \\
\hline
\end{tabular}

Tabela 7. Descrição das classes de erosão(Cenário 1)-Com práticas conservacionistas para cada município da PN1.

\begin{tabular}{|c|c|c|c|c|c|c|}
\hline \multirow[b]{2}{*}{ Município } & \multicolumn{6}{|c|}{ Área do município dentro da PN1 (\%) } \\
\hline & $\begin{array}{c}\text { Água e Área } \\
\text { Urbana }\end{array}$ & $\begin{array}{l}\text { Muito } \\
\text { Baixa }\end{array}$ & Baixa & Média & Alta & $\begin{array}{l}\text { Muito } \\
\text { Alta }\end{array}$ \\
\hline Abadia dos Dourados & 3,47 & 96,1 & 0,41 & 0,01 & 0 & 0 \\
\hline Araguari & 5,24 & 94,40 & 0,34 & 0,01 & 0,01 & 0 \\
\hline Araporã & 29,23 & 70,60 & 0,17 & 0 & 0 & 0 \\
\hline Carmo do Paranaíba & 1,25 & 98,51 & 0,22 & 0,02 & 0 & 0 \\
\hline Cascalho Rico & 18,16 & 81,83 & 0,01 & 0 & 0 & 0 \\
\hline Coromandel & 0,59 & 99,16 & 0,23 & 0,01 & 0 & 0 \\
\hline Cruzeiro da Fortaleza & 0,43 & 98,96 & 0,58 & 0,02 & 0 & 0 \\
\hline Douradoquara & 13,21 & 86,76 & 0,02 & 0 & 0 & 0 \\
\hline Estrela do Sul & 0,65 & 99,17 & 0,17 & 0 & 0 & 0 \\
\hline Grupiara & 34,98 & 65,00 & 0,01 & 0 & 0 & 0 \\
\hline Guarda-Mor & 0,04 & 99,31 & 0,59 & 0,05 & 0,01 & 0 \\
\hline Guimarânia & 0,43 & 98,94 & 0,58 & 0,05 & 0 & 0 \\
\hline Irai de Minas & 4,01 & 95,99 & 0 & 0 & 0 & 0 \\
\hline Lagamar & 0,17 & 99,45 & 0,35 & 0,02 & 0 & 0 \\
\hline Lagoa Formosa & 0,46 & 98,18 & 1,26 & 0,08 & 0,01 & 0 \\
\hline Monte Carmelo & 1,71 & 98,23 & 1,26 & 0,09 & 0,01 & 0 \\
\hline Nova Ponte & 0,49 & 99,38 & 0,13 & 0 & 0 & 0 \\
\hline Paracatu & 0,14 & 99,69 & 0,17 & 0,01 & 0 & 0 \\
\hline Patos de Minas & 1,37 & 98,09 & 0,53 & 0 & 0 & 0 \\
\hline Patrocínio & 1,20 & 98,66 & 0,13 & 0,01 & 0 & 0 \\
\hline Presidente Olegário & 0,46 & 97,75 & 1,63 & 0,10 & 0,04 & 0,02 \\
\hline Rio Paranaíba & 0,16 & 99,10 & 0,72 & 0,02 & 0 & 0 \\
\hline Romaria & 0,72 & 99,11 & 0,17 & 0 & 0 & 0 \\
\hline Serra do Salitre & 0 & 99,71 & 0,28 & 0 & 0 & 0 \\
\hline Tupaciguara & 15,99 & 86,06 & 0,86 & 0,06 & 0,01 & 0,01 \\
\hline Unaí & 0,88 & 98,91 & 0,20 & 0 & 0 & 0 \\
\hline
\end{tabular}

Também foram atribuídos valores para $\mathrm{P}$ com uso de práticas conservacionistas e sem uso de práticas conservacionistas, no mapa de uso e cobertura do solo elaborado para a bacia, por meio do SIG ArcGis. Ainda utilizando recursos do SIG ArcGIS foi calculada a média aritmética para toda a área de estudo, do fator $\mathrm{P}$ com $\mathrm{e}$ sem o uso de práticas conservacionistas.
Os valores para o fator $\mathrm{P}$ com o uso de práticas conservacionistas (Figura 10) variaram de 0 a 0,5. Conforme pode ser observado na legenda desta, a representação foi dividida em quatro classes, sendo a primeira com o valor 0 (zero), extratificada por se constituir de áreas de água, uma classe com valores superiores a 0 até 0,1 , constituída por regiões de mata, a terceira 
classe com valores superiores a 0,01 até 0,04 , em regiões ocupadas por cerrado, eucalipto e pinus e uma quarta classe com valores superiores à 0,04 e como máximo 0,5, em regiões com a presença de pastagens e regiões agrícolas. A média obtida para toda a área de estudo com o uso de práticas conservacionistas foi de 0,35.

Os valores de $\mathrm{P}$ sem o uso de práticas conservacionistas (Figura 11) variaram de 0 a 1, também extratificada em quatro classes, diferindo do primeiro na quarta classe onde os valores são superios a 0,04 e com o máximo de 1,0 , apresentando as mesmas coberturas, porém com o emprego de práticas conservacionistas nestas. Neste segundo mapa a média obtida para toda a área de 0,71.

Após a obtenção de todos os fatores da equação proposta por Wischmeier \& Smith (1978), estes foram integrados no SIG ArcGIS por meio da ferramenta Map Calculator. Integrando-se todos os fatores considerandose os dois cenários (com práticas conservacionistas e sem práticas conservacionistas) chegando-se aos mapas apresentados na

Para os dois cenários ( 1 - com práticas conservacionistas e 2 - sem práticas conservacionistas) a faixa de variação em Ton/ha/ano é a mesma para cada classe, conforme apresentado na tabela 5 e tabela 6 , sendo que os valores para a classe Muito Alta variaram de 20 a aproximadamente 68 Ton/ha/ano para o primeiro cenário e de 20 a aproximadamente 136 Ton/ha/ano, demonstrando o aumento na quantidade de sedimentos que poderá se carreado quando práticas conservacionistas não são adotadas no campo. Percebe-se pelas tabelas acima o aumento de todas as classes de perda de solo quando não se adotam práticas conservacionistas. As mesmas observações são constatadas quando se verifica a percentagem da área das classes de erosão de cada município, considerando apenas a área do município inserida na PN1, adotando-se as práticas conservacionistas (Tabela 7) e sem adotá-las (Tabela 8).

Os resultados obtidos para a bacia, considerando-se os dois cenários também foram confrontados com os dados de qualidade de água de quatro pontos de monitoramento do IGAM na bacia, quais sejam o ponto PB003, PB005, PB007 e o ponto PB009. Foram delimitadas, a princípio, as bacias para os quatro pontos de monitoramento de qualidade da água, em virtude da disponibilidade dos dados de sólidos totais para estes pontos (Figura 14).

Foram obtidos o monitoramento de sólidos totais dos pontos PB003, PB005, PB007 e PB009 de outubro de 1997 à outubro de 2007. Estes dados foram plotados na figura 15. Os pontos de monitoramento PB003 e PB005 apresentaram uma elevada concentração de sólidos totais no período chuvoso, já os pontos PB009 e PB007 apresentaram uma distribuição mais uniforme ao longo do período monitorado.

Os pontos PB007 e PB009 apresentam bacias hidrográficas (bacias de contribuição) com áreas reduzidas quando comparadas ás bacias dos pontos PB003 e PB005, sendo que este fato poderia interferir diretamente para a redução de sólidos totais dissolvidos quando se compara os teores advindos destas duas bacias com os que seriam carreados nas bacias dos pontos PB003 e PB005. Assim seria esperado a redução da magnitude e não a distribuição das concentrações ao longo do ano hidrológico.

Observa-se o percentual de cada classe de potencial de perdas de solo, da área de cada bacia, nota-se que as bacias dos pontos PB007 e PB009 apresentam áreas classificadas como sendo Alta, quando se adota práticas conservacionistas (cenário 1) e a presença da classe Muito Alta, quando não se adota práticas conservacionistas (cenário 2 ). Todavia em percentagens muito baixas, como pode ser observado na tabela 9 e na tabela 10 .

Assim grande variação na concentração de sólidos totais e o considerável incremento em seus valores nos pontos PB003 e PB005 podem ser consequência direta do tamanho da bacia de contribuição, visto que todas as bacias apresentam um comportamento muito semelhante em relação às classes de potencial de perdas de solos. Além disso, a configuração espacial das quatro bacias confere a elas condições hidrosendimentológicas muito semelhantes, visto que todas apresentam o mesmo formato (alongados), além de acarretar em um comportamento do escoamento superficial semelhante, tempos de concentração do fluxo semelhantes, contudo proporcional ao tamanho de cada uma, mas sem apresentar picos (como ocorre em bacias circulares). Estas características estão diretamente relacionadas à energia cinética do carreamento, assim, consequentemente influenciam no carreamento de sedimentos.

\section{CONSIDERAÇÕES FINAIS}

Os mapas de erodibilidade e erosividade permitem dar uma indicação das principais áreas que poderiam ser contribuintes para o assoreamento dos rios e lagos da região. Porém, há que se determinar os outros fatores da EUPS, no caso, uso do solo, comprimento e declividade das encostas e práticas agrícolas para darmos uma real inferência sobre os locais de perca de solo da região. Mas, há também a necessidade da determinação do fator " $C$ " em épocas distintas do ano e de um banco de dados com mais informações de erodibilidade do solo ("K") visando uma melhor acurácia na predição de áreas com maiores potenciais contribuintes para o assoreamento dos corpos hídricos.

A metodologia empregada para o cálculo do fator " $\mathrm{L}$ " mostrou-se eficiente na medida em que os valores encontrados foram próximos a valores obtidos por outros autores e estudos, sendo coerentes com as características morfológicas da área estudada.

O parâmetro " $\mathrm{M}$ " poderia ser melhor trabalhado com a obtenção deste para classes de declividades maiores do que as contempladas pela proposta de Desmet e Govers (1996), contudo não inviabiliza este trabalho, visto que grande parte da área estudada apresenta declividades dentro das classes propostas. 
O valor do fator "P" associado a cada classe de uso foi atribuído tendo por base a generalização de cada classe, não definindo a classe de cultivo, pois o trabalho foi elaborado para uma escala regional.

Os fatores que mais contribuíram para a variação no potencial erosivo, considerando os dois cenários (cenário 1 - com práticas conservacionistas e cenário 2 - sem práticas conservacionistas) foram o comprimento da vertente e a declividade para todos os municípios inclusos na bacia PN1-IGAM. As áreas que apresentaram variação no potencial eram ocupadas por pastagens, matas de galeria e agricultura, sendo esta última em menor percentagem.

Os resultados apresentados para o potencial erosivo foram abordados de forma qualitativa, em virtude da escala de trabalho e do objetivo final deste, sendo considerados cenários que demonstram a variação do potencial erosivo da bacia PN1 quando se emprega práticas conservacionistas. Estes resultados permitem uma visão macro do comportamento do potencial erosivo na bacia, dando subsídios para o planejamento de gestores de órgãos públicos ou privados para o direcionamento de suas ações.

Os resultados deste trabalho foram repassados para o IGAM e para a EMATER, que demonstraram interesse e os solicitaram. Estas entidades já vêm atuando na bacia e salientaram que estes resultados poderão possa contribuir com as ações que estes já desenvolvem.

\section{AGRADECIMENTOS}

À Fundação de Amparo à Pesquisa do Estado de Minas Gerais - FAPEMIG, pela disponibilização dos recursos que permitiram subsidiar os custos deste trabalho. Aos pesquisadores Mark Leabdri Naves Silva (UFLA), Elpídio Inácio Fernandes Filho (UFV), Thomaz Correa e Castro da Costa (EMBRAPA), Daniel Pereira Guimarães (EMBRAPA) e Fábio Giannetti (IPLA - Itália) pela colaboração na confecção dos mapas.

\section{REFERÊNCIAS BIBLIOGRÁFICAS}

ANA - Agência Nacional de Águas. 2008. Sistema de informações hidrológicas. Disponível em: http://hodroweb.ana.gov.br. Acessado em 08 jun 2008.

Araújo Júnior G. 1997. Aplicação dos modelos EUPS e MEUPS na bacia do Ribeirão Bonito (SP) através de técnicas de sensoriamento remoto e geoprocessamento. Dissertação de Mestrado, Mestrado em Sensoriamento Remoto, Instituto Nacional de Pesquisas Espaciais, 122 p.

Bertol I 1993. Índice de erosividade (EI30) para Lages (SC) - 1a aproximação. Pesquisa Agropecuária Brasileira, 28: 515-521.

Bertol I 1994. Avaliação da erosividade da chuva na localidade de Campos Novos (SC) no período de 19811990. Pesquisa Agropecuária Brasileira, 29: 453-458.
Bertolino J \& Lombardi Neto F (Eds.) 1992. Conservação do Solo. Ícone, São Paulo, 335 pp.

Bertolinio J \& Lombardi Neto F (Eds.) 1993. Conservação do Solo. Ícone, São Paulo, 335 pp.

Brito JLS., Lima SC., Shiki S., Moreira MR. 1998. Uso do geoprocessamento na estimativa de perda de solo por erosão laminar em Irai de Minas - MG. In: Simpósio Brasileiro de Sensoriamento Remoto, 9, Atas, p. 501-512.

Cabral JBP. 2005. Estudo do processo de assoreamento em reservatórios. Caminhos de Geografia, 14: 62-69.

Carvalho MP. 1987. Erosividade da chuva: distribuição e correlação com as perdas de solo de Mococa (SP). Dissertação de Mestrado, Escola Superior de Agricultura Luiz de Quiroz, Universidade de São Paulo, $104 \mathrm{p}$.

Cecílio RA. 2008. Equação universal de perdas de solos (EUPS ou USLE, em inglês). Disponível em: www.nedtc.ufes.br/prof/Roberto/disciplinas/manej o. Acessado em 21 ago 2013.

Coelho AP. 2001. Fator erosividade da chuva do município de Votuporanga (SP). Dissertação de Mestrado, Mestrado em Agronomia, Universidade Estadual Paulista Júlio de Mesquita Filho, 101 p.

Colodro G. 1999. Erosividade da chuva: distribuição e correlação com a precipitação pluviométrica de Teodoro Sampaio (SP). Dissertação de Mestrado, Mestrado em Agronomia, Universidade Estadual Paulista Júlio de Mesquita Filho, 76 p.

Duke GD., Kienzle SW., Johnson DL., Byrne JM. 2003. Improving overland flow routing by incorporating ancillary road data into digital elevation models. International Journal of Spatial Hydrology, 2:1-27.

ESRI. Disponível em : http://www.esri.com/. Acessado em 03 fev 2008

Farinasso M., Júnior OAC., Guimarães RF., Gomes RAT., Ramos VM. 2006. Avaliação qualitativa do potencial de erosão laminar em grande área por meio da EUPS utilizando novas metodologias em SIG para os cálculos dos seus fatores na região do Alto Parnaíba PI-MA. Revista Brasileira de Geomorfologia, 7: 1-15.

Fournier F. 1956. The effect of climatic factors on soil erosion estimates of solids transported in suspension in runoff. Association Hydrologic Int. Public, 38: 1-6.

Fujihara AK. 2002. Predição de erosão e capacidade de uso do solo numa microbacia do oeste paulista com suporte de geoprocessamento. Dissertação de Mestrado, Escola Superior de Agricultura Luiz de Queiroz, Universidade de São Paulo, 136 p.

Gameiro MG. 2003. Avaliação de métodos para obtenção dos fatores "L" e "S" da EUPS numa microbacia, via geoprocessamento e banco de dados. Dissertação de Mestrado, Mestrado em Sensoriamento Remoto, Instituto Nacional de Pesquisas Espaciais, $138 \mathrm{p}$.

Gomes IA., Palmieri F., Baruqui AM., Motta PEF., Naime UJ. 1982. Levantamento de reconhecimento de média intensidade e aptidão agrícola dos solos do Triângulo Mineiro. Boletim de Pesquisa, Rio de Janeiro, $526 \mathrm{pp}$ 
Tabela 8. Descrição das classes de erosão (Cenário 2)-Sem práticas conservacionistas para cada município da PN1.

\begin{tabular}{|c|c|c|c|c|c|c|c|}
\hline & \multicolumn{7}{|c|}{ Área do município dentro da PN1 (\%) } \\
\cline { 2 - 7 } Município & $\begin{array}{c}\text { Água e Área } \\
\text { Urbana }\end{array}$ & $\begin{array}{c}\text { Muito } \\
\text { Baixa }\end{array}$ & Baixa & Média & Alta & $\begin{array}{c}\text { Muito } \\
\text { Alta }\end{array}$ \\
\hline Abadia dos Dourados & 3,47 & 95,23 & 1,20 & 0,08 & 0,01 & 0,01 \\
\hline Araguari & 5,24 & 93,94 & 0,73 & 0,06 & 0,01 & 0,01 \\
\hline Araporã & 29,23 & 70,15 & 0,61 & 0,01 & 0 & 0 \\
\hline Carmo do Paranaíba & 1,25 & 98,01 & 0,66 & 0,06 & 0,02 & 0 \\
\hline Cascalho Rico & 18,16 & 81,74 & 0,10 & 0 & 0 & 0 \\
\hline Coromandel & 0,59 & 98,69 & 0,65 & 0,04 & 0,02 & 0 \\
\hline Cruzeiro da Fortaleza & 0,43 & 97,57 & 1,90 & 0,08 & 0,02 & 0 \\
\hline Douradoquara & 13,21 & 86,69 & 0,10 & 0 & 0 & 0 \\
\hline Estrela do Sul & 0,66 & 98,79 & 0,53 & 0,02 & 0 & 0 \\
\hline Grupiara & 37,98 & 64,83 & 0,19 & 0 & 0 & 0 \\
\hline Guarda-Mor & 0,04 & 98,24 & 1,54 & 0,12 & 0,05 & 0,02 \\
\hline Guimarânia & 0,43 & 97,75 & 1,67 & 0,10 & 0,05 & 0 \\
\hline Irai de Minas & 4,01 & 95,99 & 0 & 0 & 0 & 0 \\
\hline Lagamar & 0,18 & 98,42 & 1,37 & 0,02 & 0,02 & 0 \\
\hline Lagoa Formosa & 0,46 & 96,44 & 2,66 & 0,34 & 0,09 & 0,01 \\
\hline Monte Carmelo & 1,71 & 98,04 & 0,28 & 0 & 0 & 0 \\
\hline Nova Ponte & 0,49 & 99,22 & 0,28 & 0 & 0 & 0 \\
\hline Paracatu & 0,14 & 99,24 & 0,60 & 0,01 & 0,01 & 0 \\
\hline Patos de Minas & 1,37 & 96,96 & 1,60 & 0,06 & 0 & 0 \\
\hline Patrocínio & 1,21 & 98,32 & 0,45 & 0,02 & 0 & 0 \\
\hline Presidente Olegário & 0,46 & 95,67 & 3,36 & 0,36 & 0,10 & 0,06 \\
\hline Rio Paranaíba & 0,16 & 97,94 & 1,79 & 0,09 & 0,02 & 0 \\
\hline Romaria & 0,72 & 98,51 & 0,73 & 0,04 & 0 & 0 \\
\hline Serra do Salitre & 0 & 99,05 & 0,90 & 0,04 & 0,01 & 0 \\
\hline Tupaciguara & 15,99 & 81,87 & 1,88 & 0,18 & 0,06 & 0,02 \\
\hline Unaín & 0,88 & 98,35 & 0,73 & 0,03 & 0 & 0 \\
\hline
\end{tabular}

Tabela 9. Descrição das classes de erosão(Cenário 1)-Com práticas conservacionistas.

\begin{tabular}{|c|c|c|c|c|}
\hline $\begin{array}{c}\text { Classes de potencial de } \\
\text { perdas de solos }\end{array}$ & PB003 & PB005 & PB007 & PB009 \\
\hline Água e Área Urbana & Área em \% & Área em \% & Área em \% & Área em \% \\
\hline Muito Baixa & 0,65 & 0,89 & 2,30 & 2,97 \\
\hline Baixa & 98,75 & 98,48 & 97,36 & 96,61 \\
\hline Média & 0,57 & 0,59 & 0,27 & 0,34 \\
\hline Alta & 0,03 & 0,03 & 0,04 & 0,05 \\
\hline Muito Alta & 0,00 & 0,00 & 0,02 & 0,03 \\
\hline TOTAL & 0,00 & 0,00 & 0,00 & 0,00 \\
\hline
\end{tabular}

Tabela 10. Descrição das classes de erosão(Cenário 2)-Sem práticas conservacionistas.

\begin{tabular}{|c|c|c|c|c|}
\hline \multirow{2}{*}{$\begin{array}{c}\text { Classes de potencial de } \\
\text { perdas de solos }\end{array}$} & PB003 & PB005 & PB007 & PB009 \\
\cline { 2 - 5 } & Área em \% & Área em \% & Área em \% & Área em \% \\
\hline Água e Área Urbana & 0,65 & 0,89 & 2,30 & 2,97 \\
\hline Muito Baixa & 97,75 & 97,42 & 96,94 & 96,09 \\
\hline Baixa & 1,45 & 1,55 & 0,63 & 0,78 \\
\hline Média & 0,11 & 0,10 & 0,07 & 0,09 \\
\hline Alta & 0,03 & 0,03 & 0,04 & 0,05 \\
\hline Muito Alta & 0,00 & 0,00 & 0,02 & 0,03 \\
\hline TOTAL & $\mathbf{1 0 0 , 0 0 0}$ & $\mathbf{1 0 0 , 0 0 0}$ & $\mathbf{1 0 0 , 0 0 0}$ & $\mathbf{1 0 0 , 0 0 0}$ \\
\hline
\end{tabular}




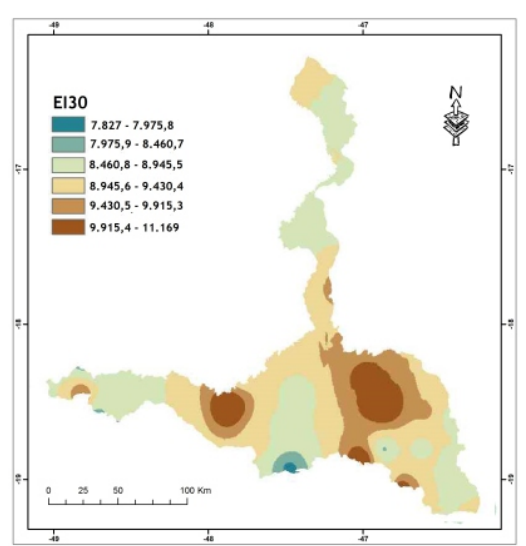

Figura 4. Mapa do EI30 (Fator " $R$ ")

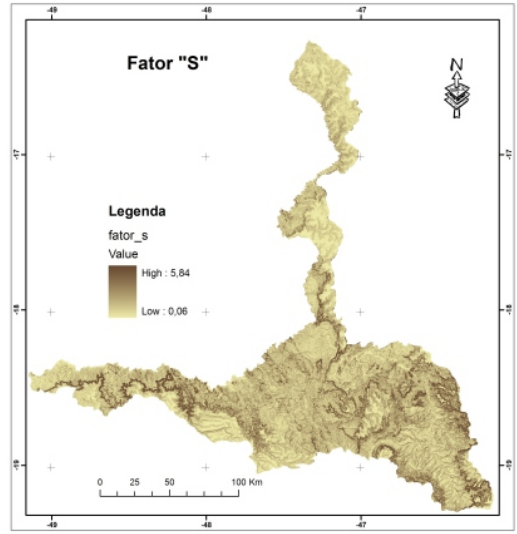

Figura 7. Fator "S" para a área de estudo.

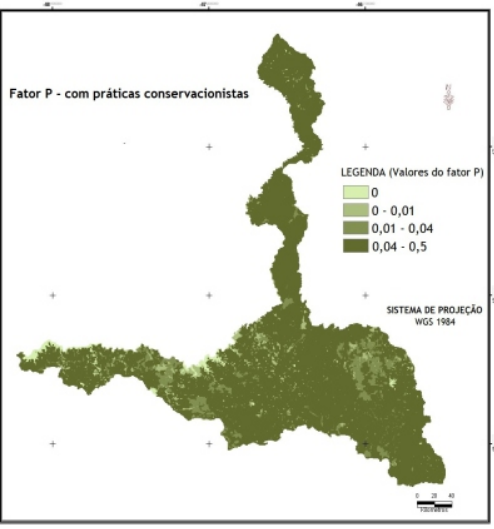

Figura 10. Mapa fator " $P$ " com o uso de práticas conservacionistas.

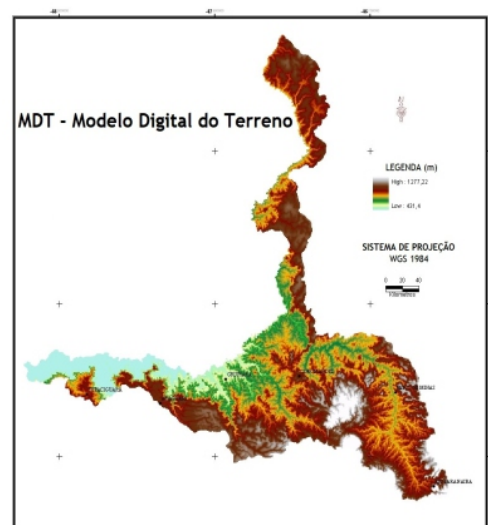

Figura 5. Modelo Digital de Elevação da área de estudo.

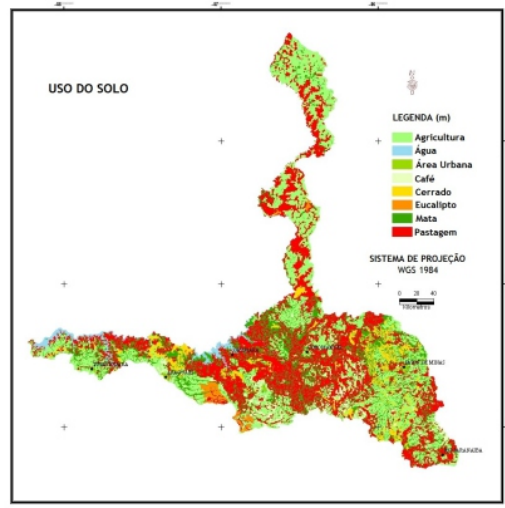

Figura 8. Mapa de uso e ocupação da bacia PN1.

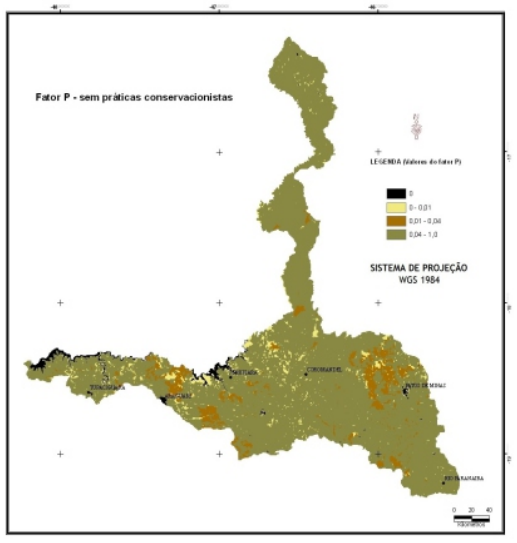

Figura 11. Mapa fator " $P$ " sem o uso de práticas conservacionistas.

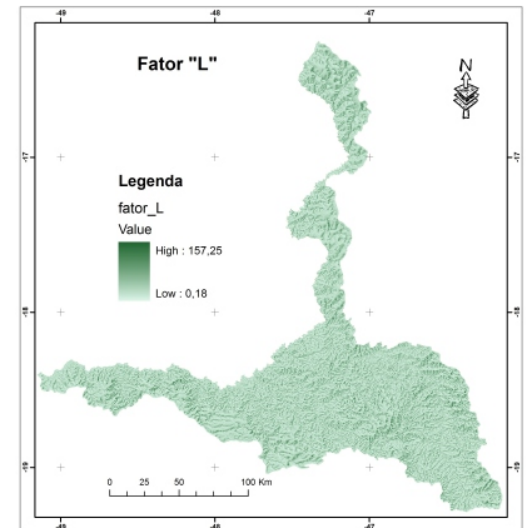

Figura 6. Mapa gerado para o Fator L.

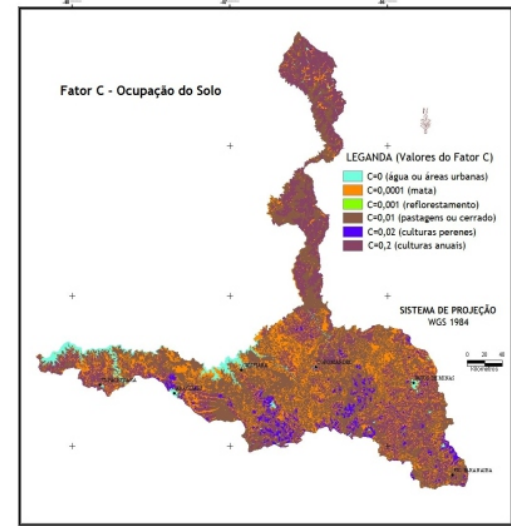

Figura 9. Mapa fator " $C$ " - uso e manejo do solo.

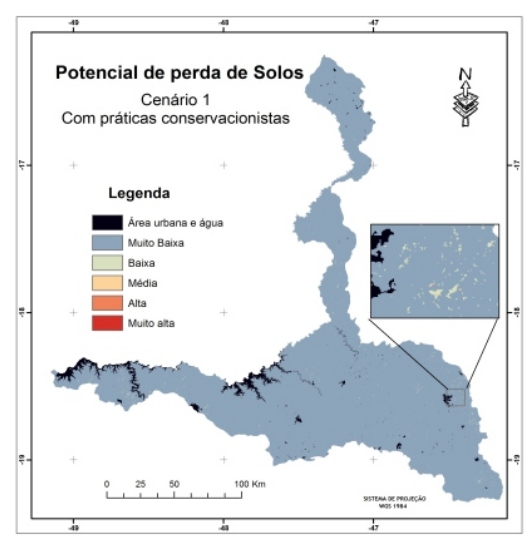

Figura 12. Potencial de perda de solos (Cenário 1).

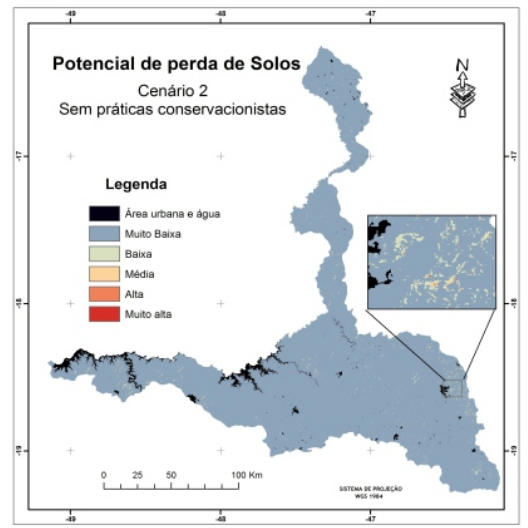

Figura 13. Potencial de perda de solos (Cenário 2).

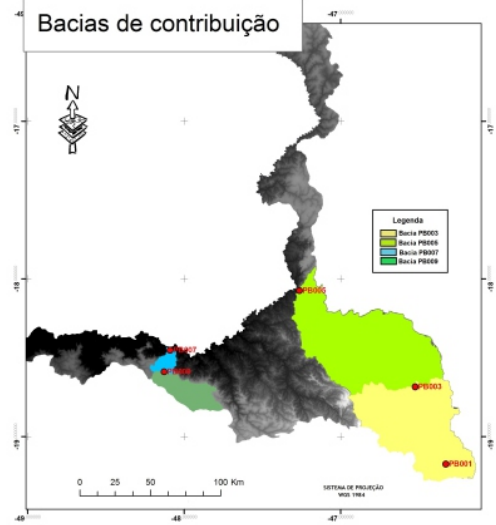

Figura 14. Bacias de contribuição dos pontos PB003, PB005, PB007 e PB009 do IGAM. 
IGAM - Instituto Mineiro de Gestão das Águas. Relatório de pontos de monitoramento. Disponível em http://www.igam.mg.gov.br/. Acessado em 16 mai 2008.

Lal R (Ed) 1988. Soil erosion: research methods. CRC Press, [s.I.], $352 \mathrm{pp}$.

Lombardi Neto F \& Moldenhauer WC. 1992. Erosividade da chuva: sua distribuição e relação com as perdas de solo em Campinas (SP). Bragantia, 51: 189-196.

Lopes AV. 1993. Aplicação de métodos de previsão de assoreamento de reservatórios. Dissertação de Mestrado, Mestrado em Engenharia Civil, Universidade Estadual de Campinas, $85 \mathrm{p}$.

Marques JJGM. 1996. Estimativas e comparações dos fatores das chuvas e erodibilidade de solos com horizonte B textural no Brasil. Dissertação de Mestrado, Mestrado em Agronomia, Universidade Federal de Lavras, $119 \mathrm{p}$.

Morais LFB., Silva V., Naschenveng TMC., Hardoin PC., Almeida JEL., Weber OLS., Boel E., Durigon V. 1991. Índice EI 30 e sua relação com o coeficiente de chuva do sudoeste do Mato Grosso. Revista Brasileira de Ciência do Solo, 15:339-344.

Motta PEF., Baruqui, AM., Santos HG. 2004. Levantamento de reconhecimento de média intensidade dos solos da região do Alto Paranaíba. Boletim de Pesquisa e Desenvolvimento, Rio de Janeiro, $238 \mathrm{pp}$.

Naime, UJ., Motta PEF., Baruqui AM., Baruqui FM., Antunes FZ., Brandão M. 1998. Levantamento de reconhecimento de média intensidade dos solos e avaliação da aptidão agrícola das terras da região geoeconômicas de Brasília e Minas Gerais. EPAMIG/EMBRAPA, Belo Horizonte, 213 pp.

Paranhas Filho AC., Fiori AP., Disperati L., Lucchesi C., Ciali A., Lastoria G. 2003. Avaliação multitemporal das perdas de solos na bacia do Rio Taquarizinho-MS. Boletim Paranaense de Geociências, 52: 49-59.

Pereira HHG. 1983. Índice de erosividade da chuva, distribuição e relações com a precipitação em Piracicaba - SP. Dissertação de Mestrado, Escola Superior de Agricultura Luiz de Queiroz, Universidade de São Paulo, 70 p.

Prochnow D., Dechen SCF., Maria IC., Castro OM., Vieira SR. 2005. Razão de perdas de terra e o fator $C$ da cultura do cafeeiro em cinco espaçamentos, em Pindorama (SP). Revista Brasileira de Ciência do Solo, 29:91-98.

Ribeiro LS \& Alves MG. 2007. Quantificação de perda de solo por erosão no município de Campos dos Goytacazes/RJ através de técnicas de geoprocessamento. Em: Simpósio Brasileiro de Sensoriamento Remoto, 13, Atas, p. 3039-3046.

Roque CG., Carvalho MP., Prado RM. 2001. Fator erosividade da chuva de Piraju (SP): distribuição, probabilidade de ocorrência, período de retorno e correlação com o coeficiente de chuva. Revista Brasileira de Ciência do Solo, 25: 147-156.
Schwab GO., Fangmeier DD., Eliot WJ., Frevert RK. (Eds.) 1981. Soil and water conservation enginnering. John Wiley \& Sons, [s.I], $526 \mathrm{pp}$.

Silva VC. 2003. Cálculo automático do fator topográfico (LS) da EUOS, na bacia do Rio Paracatu. Pesquisa Agropecuária Tropical, 33: 29-34.

Silva LF. 2007. A construção de um índice de sustentabilidade ambiental agrícola (ISA): uma proposta metodológica. Tese de Doutorado, Instituto de Economia, Universidade Estadual de Campinas, $214 p$.

Silva MLN., Freitas PL., Blancaneaux P., Curi N. 1997. Índices de erosividade das chuvas da região de Goiânia, GO. Pesquisa Agropecuária Brasileira, 32:977-985

Silva MLN., Curi N., Lima JMF., Martins M. 2000. Avaliação de métodos indiretos de determinação da erodibilidade de latossolos brasileiros. Pesquisa Agropecuária Brasileira, 35:1207-1220.

Sosa DR. 1987. Erosividade da chuva: distribuição e correlação com as perdas de solo para Pindorama, São Paulo, Brasil. Dissertação de Mestrado, Escola Superior de Agricultura Luiz de Queiroz, Universidade de São Paulo, 105 p.

Tomazoni JC., Mantovani LE., Bittencourt AVL., Filho EFR. 2005. A sistematização dos fatores da EUPS em SIG para quantificação da erosão laminar na bacia do Rio Anta Gorda (PR). Estudos Geográficos, 3:01-21.

Wischmeier W \& Smith D (Eds.) 1978. Predicting rainfall erosion losses: a guide to conservation planning. Hyattsville, [s.I.], 62 pp. 